\title{
High Coronary Collateral Circulation Increases Left Ventricular Reverse Remodeling Event in Patients with Chronic Ischaemic Heart Disease Underwent Coronary Artery Bypass Surgery
}

\author{
Ignatius F. Yuwono', Udin Bahrudin', Misbah H. Cahyadi', Ilham Uddin', \\ Yan Herry', Sodiqur Rifai', Sahal Fatah', Hardian Hardian', \\ Mochamad A. Nugroho', Susi Herminingsih'
}

\footnotetext{
' Department of Cardiology and Vascular Medicine, Faculty of Medicine, Diponegoro University - Dr. Kariadi General Hospital, Semarang, Indonesia.

${ }^{2}$ Department of Cardiothoracic Surgery, Faculty of Medicine, Diponegoro University -

Dr. Kariadi General Hospital, Semarang, Indonesia.

${ }^{3}$ Department of Physiology, Faculty of Medicine, Diponegoro University, Semarang, Indonesia.
}

\section{Correspondence:}

Ignatius Faizal Yuwono, Department of Cardiology and Vascular Medicine, Faculty of Medicine, Diponegoro University - Dr. Kariadi General Hospital, Semarang, Indonesia. Columbia Asia Hospital, Semarang Indonesia. Email: ignatiusfaizal@gmail.com

\begin{abstract}
Background: Coronary collateral circulation (CCC) is linked to myocardial remodeling severity in patients with chronic ischaemic heart disease (IHD). However its effect on left ventricular reverse remodeling (LVRR) in patients with chronic IHD underwent coronary artery bypass surgery (CABG) has never been reported. Purpose of this study was to investigate the effect of CCC grade on the LVRR event in patients with chronic IHD underwent CABG.

Methods: This prospective cohort study was performed in patients with chronic IHD underwent CABG. The CCC was classified using Rentrop collateral score, i.e low CCC grade (Rentrop score 0 and I) and high CCC grade (Rentrop score 2 and 3 ). LVRR event was defined as a reduction in left ventricular end systolic volume (LVESV) of $10 \%$ or more, measured by a 3D echocardiography at 1.5 months post CABG compared to the baseline before CABG.

Results: A total of 22 patients ( $81.8 \%$ male) with mean of age 58.6 years old were enrolled. LVRR occurred in $50 \%$ patients. LVRR event was significantly higher in the patients with high CCC grade than the low CCC grade patients $(p=0.009)$. The high CCC grade increased LVRR event independently (odds ratio $=26.67$; relative risk $=6.93$ ).

Conclusion: High coronary collateral circulation may increase left ventricular reverse remodeling event in patients with chronic ischemic heart disease underwent coronary artery bypass surgery.
\end{abstract}

(Indonesian J Cardiol. 2020;4I:2 I3-22 I)

Keywords: coronary collateral circulation; left ventricular reverse remodeling; chronic ischaemic heart disease; coronary artery bypass surgery; 3D echocardiography 


\section{Introdution}

L

eft ventricular reverse remodeling (LVRR) is a reduction in left ventricular end systolic volume (LVESV) of $10 \%$ or more compared to the baseline. It is observed in diverse clinical settings including in patients with chronic ischaemic heart disease (IHD) underwent coronary revascularization. ${ }^{1}$ Either LVESV or left ventricular ejection fraction (LVEF) can be used as parameter for measuring left ventricular function, however LVESV is less preload dependent compared to the LVEF. ${ }^{2}$

Coronary artery bypass grafting (CABG) is effective in improving symptoms and survival rate in patients with chronic IHD by promoting LVRR. ${ }^{3}$ Coronary collateral circulation (CCC) is alternative source of blood supply for myocardium at risk of ischaemia caused by a reduced coronary blood flow through native coronary arteries. Evidence shows protective role of CCC in chronic IHD patients. ${ }^{4,5,6}$ Higher CCC supply is associated with increased myocardial viability and improvement of regional and global cardiac systolic and diastolic function in patients with chronic IHD. ${ }^{7,8,9}$

Several methods are used for assessing CCC grade, including collateral flow index, collateral connection score, washout callorimetry, and perfusion imaging. The visual collateral connection method using Rentrop score is the most common used method. ${ }^{10}$ It is simple, could be implemented clinically and has been validated. ${ }^{11}$

Cardiac magnetic resonance imaging is the gold standard method to assess ventricular volume but it has shortcoming related with its availability, affordability and usability. In comparison to the gold standard, real time 3D Echocardiography (RT3DE) has higher accuracy and reproducibility, cost effective, safe and applicable for patients, and thus it is becoming the first choice method in assessing left ventricular volume. ${ }^{12,13}$ However, there is no study reporting the effect of CCC on the LVRR event in patients with chronic IHD underwent CABG, measured by RT3DE method. This study investigated the effect of CCC grade on the LVRR event in patients with chronic IHD underwent CABG using full volume RT3DE.

\section{Methods}

\section{Subject of study}

This observational, prospective cohort study was performed in 24 patients with chronic IHD underwent CABG at the Dr. Kariadi General Hospital, Semarang, Indonesia from April to September 2018. We included patient with LVEF $<50 \%$ and end diastolic wall thickness more than $6 \mathrm{~mm}$ with sinus rhythm. Patient with left bundle branch block (LBBB), acute coronary syndrome $(\mathrm{ACS})<1.5$ months prior to $\mathrm{CABG}$, concomitant congenital heart disease, prior history of CABG, concomitant valve surgery, or poor echo window were excluded; and those with periprocedural infarction, having acute coronary syndrome, or death during 1.5 months follow-up were dropped out. A consecutive sampling method was used. The University and Hospital Ethical Committee approved the study, and written informed consent was obtained from all of the patients. Investigational procedures were in accordance with institutional guidelines.

\section{Assessment of coronary collateral circulation and left ventricular reverse remodeling}

Demographic, clinical and echocardiographic data were collected from all subjects. CCC grade of the coronary angiogram before CABG was assessed using the Rentrop collateral score, ${ }^{14}$ while the occurrence of LVRR was assessed with the $3 \mathrm{D}$ echocardiography study prior and 1.5 months post CABG.

The Rentrop collateral score was as follow: score $0=$ no filling from collateral, 1 = filling of side branches of the artery via collateral channels without visualization of the epicardial segment, 2 = partial filling of the epicardial segment via collateral channels, 3 = complete filling of the epicardial segment of the artery via collateral channels. ${ }^{14}$ In patients with more than 1 coronary collaterals, the highest collateral score was used. Patients were classified as having low CCC grade (Rentrop score 0 and 1 ) or high CCC grade (Rentrop score 2 and 3). Collateral grade was assessed by two senior interventional cardiologists with blinding to the clinical data of the patients. When there was a disagreement between them, the collateral grade was decided by the third observer. 
Indonesian Journal of Cardiology

Table 1. Baseline clinical and echocardiographic characteristic of patients with $(+)$ and without (-) left ventricular reverse remodeling

\begin{tabular}{|c|c|c|c|}
\hline Parameter & $\begin{array}{c}\operatorname{LVRR}(-) \\
(\mathrm{n}=11)\end{array}$ & $\begin{array}{c}\operatorname{LVRR}(+) \\
(\mathrm{n}=11)\end{array}$ & $\mathbf{p}$ \\
\hline \multicolumn{4}{|l|}{ Clinical Characteristic } \\
\hline - Low & $8(88.9)$ & $1(11.1)$ & $0.008 \mathrm{~b}$ \\
\hline - High & $3(23.1)$ & $10(76.9)$ & \\
\hline Age (years) & $\begin{array}{c}61.72 \pm 8.93 \\
62.42(48.42-79.83)\end{array}$ & $\begin{array}{c}55.54 \pm 8.76 \\
55.92(42.58-69.92)\end{array}$ & $0.117 \mathrm{a}$ \\
\hline \multicolumn{4}{|l|}{$\operatorname{Sex}(n(\%))$} \\
\hline $\begin{array}{ll}\text { - } & \text { Male } \\
\text { - } & \text { Female }\end{array}$ & $\begin{array}{c}8(44.4) \\
3(75)\end{array}$ & $\begin{array}{c}10(55.6) \\
1(25)\end{array}$ & $0.586 \mathrm{~b}$ \\
\hline Diabetes Mellitus (n(\%)) & $5(83.3)$ & $1(16.7)$ & $0.149 \mathrm{~b}$ \\
\hline Hypertension (n(\%)) & $8(53.3)$ & $7(46.7)$ & $1.000 \mathrm{~b}$ \\
\hline Chronic kidney disease $(\mathrm{n}(\%))$ & - & - & * \\
\hline $\begin{array}{l}\text { LVR severity before CABG } \\
(\mathrm{ml} / \mathrm{m} 2)\end{array}$ & $\begin{array}{c}72.27 \pm 36.1 \\
61.13(35.09-128.07)\end{array}$ & $\begin{array}{c}62.70 \pm 22.67 \\
55.84(36.45-116.78)\end{array}$ & $0.467 \mathrm{a}$ \\
\hline History of ACS (n(\%)) & $7(50)$ & $7(50)$ & $1.000 \mathrm{~b}$ \\
\hline Anti-remodeling drugs $(\mathrm{n}(\%))$ & $11(50)$ & $11(50)$ & $*$ \\
\hline - $\quad \beta$-blocker & $8(44.4)$ & $10(55.6)$ & $0.586 \mathrm{~b}$ \\
\hline - ACE-inhibitor/ARBs & $10(50)$ & $10(50)$ & $1.000 \mathrm{~b}$ \\
\hline - $\quad$ MRA & $5(55.6)$ & $4(44.4)$ & $1.000 \mathrm{~b}$ \\
\hline \multicolumn{4}{|l|}{ Baseline Echocardiographic } \\
\hline Characteristic & $80.92 \pm 48.71$ & $67.95 \pm 32.48$ & $0.974 \mathrm{c}$ \\
\hline \multirow{2}{*}{ LVESV 3D full-volume (ml) } & $58.1(33-168.2)$ & $62.1(37.6-148)$ & \\
\hline & $48.64 \pm 28.27$ & $38.72 \pm 17.47$ & $0.718 \mathrm{c}$ \\
\hline \multirow[t]{2}{*}{ LVESV 3D full-volume (ml) } & $36.31(17.74-92.93)$ & $31.87(21.86-80.87)$ & \\
\hline & $121.95 \pm 59.36$ & $112.45 \pm 43.81$ & $0.674 \mathrm{a}$ \\
\hline \multirow[t]{2}{*}{ LVEDV 3D full-volume (ml) } & $97.8(65-231.8)$ & $103.3(62.7-231.7)$ & \\
\hline & $73.55 \pm 34.77$ & $64.08 \pm 23.1$ & $0.462 \mathrm{a}$ \\
\hline LVEDVi 3D full-volume (ml/ & $61.13(35.11-128.07)$ & $55.84(36.45-116.78)$ & \\
\hline $\mathrm{m} 2)$ & $\begin{array}{c}37.32 \pm 9.64 \\
40.6(24.6-49.4)\end{array}$ & $\begin{array}{c}40.89 \pm 6.48 \\
42.3(30.8-49.9)\end{array}$ & $0.323 \mathrm{a}$ \\
\hline LVEF 3D full-volume (\%) & $\begin{array}{c}1.61 \pm 0.44 \\
1.44(1.06-2.13)\end{array}$ & $\begin{array}{c}1.42 \pm 0.28 \\
1.31(1.13-2)\end{array}$ & $0.373 c$ \\
\hline WMSI & & & \\
\hline
\end{tabular}

(+) with and (-) without left ventricular reverse remodeling, aindependent $t$-test; bFisher's exact test; cMann-Whitney test; ${ }^{*}$ statistical analysis could not be proceeded; LVRR : left ventricular reverse remodeling; CCC : coronary collateral circulation; LVR: left ventricular remodeling; $C A B G$ : coronary artery bypass surgery; $A C S$ : acute coronary syndrome; ACE-inhibitor : Angiotensin Converting Enzyminhibitor; ARBs: Angiotensin-Receptor Blockers; MRA : Mineralocorticoid/Aldosterone Receptor Antagonist; LVESV: left ventricular end systolic volume; LVESVi: left ventricular end systolic volume index; LVEDV: left ventricular end diastolic volume; LVEDVi : left ventricular end diastolic volume index; LVEF : Left ventricular ejection fraction; WMSI : wall motion score index

LVRR was defined as a reduction in LVESV of 10\% or more at 1.5 months follow-up post CABG compared to the baseline before CABG.3.15 LVESV was assessed by employing a $3 \mathrm{D}$ full volume method, using the Philip Epic-7 Netherlands device, with the IntelliSpace Cardiovascular, Cardiovascular Image and Information Management System version 1.2, 20-06-2016 software. Offline analysis was done using the commercial software
(Qlab, version 4.0, Philips) by two senior noninvasive cardiologists with blinding to the clinical data of the patients. Left ventricular remodeling (LVR) severity was defined as a baseline left ventricular end diastolic volume (LVEDV) indexed by the body surface area. LVEDV was assessed by employing a 3D full volume method using the same device and software applied to the LVESV. 


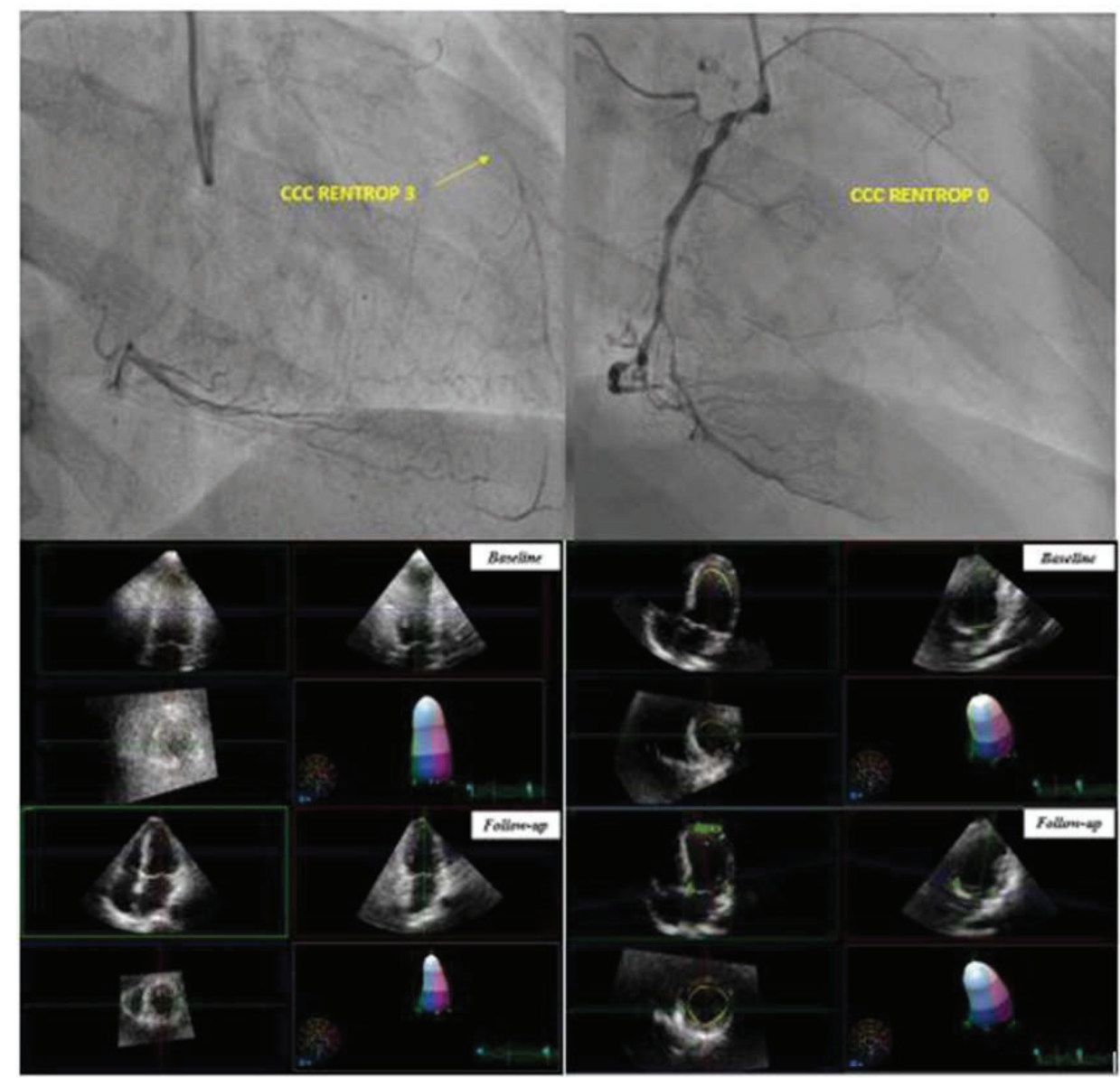

Figure 1. Representative cases of coronary collateral circulation (CCC) and left ventricular reverse remodeling (LVRR). (A) High CCC supply (Rentrop 3) from distal RCA to the CTO lesion at mid LAD. (B) LVRR event in patient with Rentrop 3 CCC supply obtained 1.5 months post CABG (baseline LVESV $=38.3 \mathrm{ml}$; follow up LVESV $=30.9 \mathrm{ml}$ ). (C) Patient underwent CABG without CCC supply (Rentrop 0). (D) Patient without CCC supply (Rentrop 0) did not experience LVRR event at 1.5 months follow up post CABG (baseline LVESV $=122.1 \mathrm{ml}$; follow-up LVESV $=118.6 \mathrm{ml}$ ) although having $\mathrm{LVEF}$ increment (baseline LVEF = 33.5\%; follow-up LVEF = 34.3\%).

\section{Statistical analysis}

Statistical analysis was done using software SPSS 25.0 (SPSS, Inc., Chicago, IL, USA). Intra-/interobserver reliability in CCC grade and LVESV were assessed using Kappa and Bland-Altman analysis, respectively. Parametric hypothesis testing were done using either Chi-Square, independent t-test or dependent t-test. Non-parametric hypothesis testing were done using either Fisher's exact, Mann-whitney or Wilcoxon test. Logistic regression multivariate analysis was used to control the effect of other variables on LVRR in order to get adjusted odds ratio (OR), 95\% confident interval (C.I.) and relative risk. A p $<0.05$ was considered statistically significant.

\section{Results}

Twenty seven patients were scheduled to have CABG in April to September 2018. Two patients did not meet inclusion criteria with $\mathrm{LVEF} \geq 50 \%$ and one patient was excluded because poor echo window. During 1.5 months follow-up, two patients were dropped out, one patient died and the other did not present at the follow-up echocardiography. Therefore 22 patients completed the study and having data before and 1.5 months after CABG. Table 1 shows the baseline clinical and echocardiographic charateristic comparison between patients with and without LVRR. Of 22 patients, 50\% (11 patients) had LVRR. There was no 
Table 2. Improvement of echocardiographic parameters in the high CCC grade group

\begin{tabular}{|c|c|c|c|}
\hline Parameter & $\begin{array}{c}\text { High CCC group } \\
(n=13)\end{array}$ & $\begin{array}{c}\text { Low CCC group } \\
(n=9)\end{array}$ & $\mathbf{p}$ \\
\hline$\Delta$ Baseline - follow-up & $-13.43 \pm 8.18$ & $-2.86 \pm 3.23$ & $<0.001 \mathrm{a}$ \\
\hline LVESV 3D full-volume (ml) & $-12.3(-35.1-(-5.3))$ & $-1,5(-10.9-(-0.4))$ & \\
\hline$\Delta$ Baseline - follow-up & $-7.63 \pm 4.2$ & $-1.66 \pm 1.68$ & $<0.001 \mathrm{a}$ \\
\hline LVESVi 3D full-volume $(\mathrm{ml} / \mathrm{m} 2)$ & $-6.59(-18.37-(-3))$ & $-0.86(-5.65-(-0.24))$ & \\
\hline$\Delta$ Baseline - follow-up & $-14.63 \pm 9.96$ & $-2.88 \pm 3.82$ & $0.004 \mathrm{a}$ \\
\hline LVEDV 3D full-volume (ml) & $-12.4(-32.9-(-0.1))$ & $-1.7(-12.6-(-0.2))$ & \\
\hline$\Delta$ Baseline - follow-up & $-8.3 \pm 5.29$ & $-1.65 \pm 1.97$ & $0.003 \mathrm{a}$ \\
\hline LVEDVi 3D full-volume $(\mathrm{ml} / \mathrm{m} 2)$ & $-7.98(-17.23-(-0.05))$ & $-1.02(-6.52-(-0.13))$ & \\
\hline$\Delta$ Baseline - follow-up & $4.44 \pm 3.93$ & $1.29 \pm 1.52$ & $0.018 \mathrm{a}$ \\
\hline LVEF 3D full-volume (\%) & $4.6(-2.1-14.3)$ & $0.7(-0.4-4.8)$ & \\
\hline$\Delta$ Baseline - follow-up & $-0.32 \pm 0.28$ & $-0.12 \pm 0.12$ & $0.037 b$ \\
\hline WMSI & $-0.25(-0.87-0)$ & $-0.07(-0.38-0.06)$ & \\
\hline
\end{tabular}

significant difference of age $(\mathrm{p}=0.117)$, sex category $(\mathrm{p}=0.586)$, diabetes mellitus $(\mathrm{p}=0.149)$, hypertension $(\mathrm{p}=1.000)$, and history of ACS $(\mathrm{p}=1.000)$ between both groups. No one had chronic kidney disease and all patients were received antiremodeling drugs therapy. The CCC grade was significantly higher in patients with LVRR than that of patients without LVRR ( $\mathrm{p}=0.008)$. Patients experienced LVRR tends to have better LVR severity before CABG compared to the patients without LVRR (baseline LVEDVi $64.08 \pm 23.1 \mathrm{ml} / \mathrm{m} 2$ and $73.55 \pm 34.77 \mathrm{ml} / \mathrm{m} 2$ respectively).

Figure $1 \mathrm{~A}$ and $1 \mathrm{~B}$ show example of a case of patient with high CCC (Rentrop 3) from the distal of right coronary artery (RCA) to the distal of left anterior descending coronary artery (LAD) with chronic total occlusion (CTO) lesion at its mid segment. Patient had a critial left main (LM) stenosis with bifurcation lesion at LM-LAD-left circumflex coronary artery (LCX); CTO lesion at mid LAD; significant ( $>50 \%)$ stenosis at the first diagonal artery and proximal-mid RCA. Three-D echocardiography obtained at 1.5 months follow-up post CABG showed a LVRR event. Figure 1C and 1D show example of a case of patient with multiple significant stenosis at proximal, mid and distal RCA, a significant stenosis at LCX, significant stenosis at proximal and distal LAD without CCC supply (Rentrop 0). This patient did not show LVRR event at 1.5 months follow up post CABG.

Table 2 shows comparison of delta baseline-followup echocardiographic parameters between the high CCC and low CCC groups. The delta baseline-followup for LVESV 3D full-volume, LVESVi 3D full-volume,

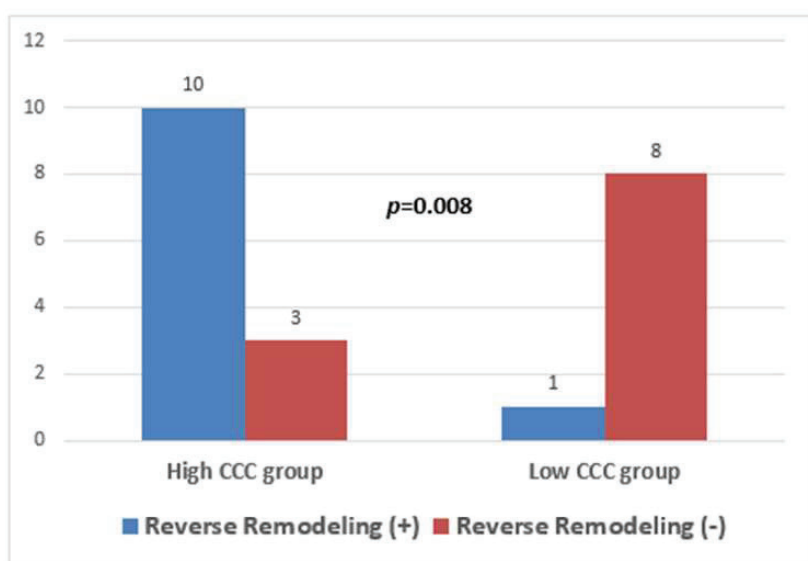

Figure 2. Left ventricular reverse remodeling event in high and low coronary collaterral circulation (CCC) groups.

LVEDV 3D full-volume, LVEDVi 3D full-volume, LVEF 3D full-volume and WMSI were significantly higher in patients with high CCC group than that of low CCC group ( $<<0.001,<0.001,0.004,0.003,0.018$ and 0.037 , respectively).

${ }^{a}$ Mann-Whitney test; bindependent t-test; LVESV : left ventricular end systolic volume; LVESVi : left ventricular end systolic volume index; LVEDV : left ventricular end diastolic volume; LVEDVi : left ventricular end diastolic volume index; LVEF : left ventricular ejection fraction; WMSI : wall motion score index.

Figure 2 shows bivariate analysis of variables affecting LVRR. There was a statistically significant difference in CCC grade between patients with and without LVRR event $(\mathrm{p}=0.008)$ whereas there was no significant differences for other variables including 
Indonesian Journal of Cardiology

Table 3. Bivariate analysis of variables affecting left ventricular reverse remodeling event post CABG

\begin{tabular}{|c|c|c|c|c|c|c|c|c|c|}
\hline & & \multicolumn{2}{|c|}{ LVRR (-) } & \multicolumn{2}{|c|}{ LVRR (+) } & \multirow{2}{*}{$\mathbf{p}$} & \multirow{2}{*}{$\begin{array}{l}\text { Relative } \\
\text { risk }\end{array}$} & \multicolumn{2}{|c|}{ 95\% C.I. } \\
\hline \multicolumn{2}{|c|}{ Parameter } & n & $\%$ & $\mathrm{n}$ & $\%$ & & & $\min$ & $\max$ \\
\hline \multirow{2}{*}{$\begin{array}{l}\text { CCC } \\
\text { grade }\end{array}$} & Low & 8 & 88.9 & 1 & 11.1 & $0.008 \mathrm{a}$ & 3.85 & 1.39 & 10.67 \\
\hline & High & 3 & 23.1 & 10 & 76.9 & & & & \\
\hline \multirow{2}{*}{$\begin{array}{l}\text { - Diabetes } \\
\text { Mellitus }\end{array}$} & Yes & 5 & 83.3 & 1 & 16.7 & $0.149 \mathrm{a}$ & 2.22 & 1.07 & 4.6 \\
\hline & No & 6 & 37.5 & 10 & 62.5 & & & & \\
\hline \multirow[t]{2}{*}{ - Hypertension } & Yes & 8 & 53.3 & 7 & 46.7 & $1.000 \mathrm{a}$ & 1.24 & 0.47 & 3.31 \\
\hline & No & 3 & 42.9 & 4 & 57.1 & & & & \\
\hline \multirow{2}{*}{$\begin{array}{l}\text { - Chronic } \\
\text { kidney disease }\end{array}$} & Yes & - & - & - & - & a & & & \\
\hline & No & 11 & 100 & 11 & 100 & & & & \\
\hline - LVR before & $\geq 75.26$ & 5 & 71.4 & 2 & 28.6 & & & & \\
\hline \multirow{3}{*}{$\begin{array}{l}\text { CABG }(\mathrm{ml} / \mathrm{m} 2) \\
\text { - History of ACS }\end{array}$} & $\leq 75.26$ & 6 & 40 & 9 & 60 & $0.361 \mathrm{a}$ & 1.79 & 0.82 & 3.88 \\
\hline & Yes & 7 & 50 & 7 & 50 & & & & \\
\hline & No & 4 & 50 & 4 & 50 & $1.000 \mathrm{a}$ & 1.00 & 0.42 & 2.38 \\
\hline \multirow{2}{*}{$\begin{array}{l}\text { Antiremodeling } \\
\text { drugs therapy }\end{array}$} & Yes & 11 & 100 & 11 & 100 & & & & \\
\hline & No & - & - & - & - & a & & & \\
\hline
\end{tabular}

aFisher's exact test; * statistical analysis could not be proceeded; LVRR : left ventricular reverse remodeling; CCC : coronary collateral circulation; $L V R$ : left ventricular remodeling; $C A B G$ : coronary artery bypass surgery; ACS : acute coronary syndrome

Table 2. Improvement of echocardiographic parameters in the high CCC grade group

\begin{tabular}{|c|c|c|c|c|c|}
\hline Parameter & Variable & P Value & OR & \multicolumn{2}{|c|}{$95 \% \mathrm{CI}$} \\
\hline \multirow{3}{*}{ Step 1a } & CCC grade (1) & 0.016 & 23.13 & 1.81 & 296.03 \\
\hline & Diabetes Mellitus(1) & 0.201 & 6.33 & 0.37 & 107.13 \\
\hline & Constant & 0.038 & 0.033 & NA & NA \\
\hline \multirow{2}{*}{ Step 2a } & CCC grade (1) & 0.009 & 26.67 & 2.31 & 308 \\
\hline & Constant & 0.05 & 0.125 & NA & NA \\
\hline
\end{tabular}

diabetes mellitus, hypertension, chronic kidney disease, LVR severity before CABG, history of acute coronary syndrome and antiremodeling drugs therapy (table 3).

Logistic regression multivariate analysis to control the effect of other variables on LVRR after CABG showed a significant association between $\mathrm{CCC}$ grade and LVRR event post CABG, $(\mathrm{p}=0.009$, adjusted $\mathrm{OR}=26.67(95 \%$ C.I. $2.31-308))($ table 4$)$

\section{Discussion}

Clinical relevance of CCC in the cardiac remodeling remains unclear. ${ }^{6}$ Result of this study adds evidence of the protective role of CCC in patients with chronic IHD underwent CABG. To the best of our knowledge, there was no study adressing the effect of CCC on LVRR based on the improvement of LVESV assessed by the RT3DE method. The important finding in this study was that the LVESV improvement rather than its LVEF was affected by degree of CCC. In addition, this study showed that $41 \%$ (9 of 22) patients with LVEF improvement did not experience LVRR event. Thus, this data support the idea that a less preload dependent parameter of left ventricular systolic function, LVESV, assessed by RT3DE is a usefull parameter to assess LVRR.

Patients underwent CABG are representative samples of population with multivessel coronary artery disease and severe myocardial remodeling who have complete revascularization in one step procedure. ${ }^{16}$ These patients are considered to be the ideal population to assess LVRR event, from which we could expect not only regional but also global myocardial recovery of viable dysfunctional myocardium. ${ }^{1}$ The global myocardial recovery is an important factor affecting 
LVESV improvement. ${ }^{1,17,18}$

Possible mechanisms of how the higher CCC affect LVRR event in chronic IHD patients underwent CABG have been proposed. Higher CCC grade increases myocardial viability ${ }^{7,8,9,19}$, reduces ischaemic event, ${ }^{20}$ myocardial infarction risk, ${ }^{8}$ and induces regional and global left ventricular myocardial function recovery after coronary revascularization. ${ }^{7,9,20}$ The reduction of ischaemic event as well as better myocardial viability and left ventricular function recovery are able to reduce the severity of LVR, reduce myocardial wall stress and secondary neurohormonal activation ${ }^{21,22}$ and increase the LVRR event post CABG. ${ }^{23,24}$

Data of this study showed that delta baselinefollow-up value for LVESV, LVESVi, LVEDV, LVEDVi, LVEF and WMSI parameters are significantly higher in the high CCC group than that of the low CCC group. This means that myocardial viability is better in the high CCC group than in the low CCC group. Patients who experienced LVRR event at 1.5 months post CABG tend to have better LVR severity prior operation than those who did not have LVRR. Taken together, the better myocardial viability and LVR severity prior CABG may be the cause of LVRR event in the patients with high CCC.

There were several limitations of this study. This study was conducted in a relatively small sample and short follow-up period, the presence of any ipsilateral collateral including bridging collateral and the dose variability of antiremodeling drug therapy in each patient were not assessed

\section{Study Limitation}

We acknowledge the small number of study subjects in our study. This might explains the rather wide confidence intervals in some of the analysis results in this study. However, the fact remains that our analyses were statistically significant and the small number of study subject of this study does not diminish the significance and importance of our findings.

\section{Conclusion}

Our data suggest that high coronary collateral circulation may increase left ventricular reverse remodeling event in patients with chronic ischaemic heart disease underwent coronary artery bypass surgery.

\section{Publication Approval}

All authors read and approved the final manuscript.

\section{Conflict of Interest}

None.

\section{Funding}

This paper received no spesific grant from any funding agency, commerical or not-for-profit sectors.

\section{Ethical Clearance}

The Ethical Committee of Dr. Kariadi General Hospital, Semarang, Indonesia approved this study, with ethical code 91/EC/FK-RSDK/II/2018.

\section{Copyright/Permissions for Fiures}

Not applicable.

\section{References}

1. Hellawell JL, Margulies KB. Myocardial Reverse Remodeling. Cardiovasc Ther. 2012;30:172-81.

2. Senior R, Lahiri A, Kaul S. Effect of revascularization on left ventricular remodeling in patients with heart failure from severe chronic ischemic left ventricular dysfunction. Am J Cardiol. 2001;88:624-9.

3. Park E-A, Lee W, Oh S-J, Kim K-B. Magnetic Resonance Imaging of Reverse Remodeling After Coronary Revascularization in Ischemic Heart Disease - Morphologic Evaluation -. Circ J. 2016;80(12):2513-9.

4. Seiler C. The Human Coronary Collateral Circulation. Heart. 2003;89:1352-7.

5. Seiler C, Stoller M, Pitt B, Meier P. The human coronary collateral circulation: development and clinical importance. Eur Heart J. 2013;34:2674- 
82.

6. Meier P, Schirmer SH, Lansky AJ, Timmis A, Pitt B, Seiler C. The collateral circulation of the heart. BMC Med. 2013;11:1-7.

7. Sabia peter J, Powers ER, Ragosta M, Sarembock IJ, Burwell LR, Kaul S. An association between collateral blood flow and myocardial viability in patients with recent myocardial infarction. $\mathrm{N}$ Engl J Med. 1992;327:1825-31.

8. Seiler C, Meier P. Historical Aspects and Relevance of the Human Coronary Collateral Circulation. Curr Cardiol Rev. 2014;10:2-16.

9. Kozman H, Cook J R, Wiseman A H, Dann R $H$, Engelman $R$ M. Presence of angiographic coronary collaterals predicts myocardial recovery after coronary bypass surgery in patients with severe left ventricular dysfunction. Circulation. 1998;98(19Suppl):II57-61.

10. Meier P, Hemingway H, Lansky AJ, Knapp G, Pitt B, Seiler C. The impact of the coronary collateral circulation on mortality : a meta-analysis. Eur Heart J. 2012;33:614-21.

11. Berry C, Balachandran KP, Allier PLL, Lespe J, Bonan R, Oldroyd KG. Importance of Collateral Circulation in Coronary Heart Disease. Eur Heart J. 2007;28:278-91.

12. Monaghan MJ. Role of Real Time 3D Echocardiography in Evaluating The Left Ventricle. Heart. 2006;92:131-6.

13. Lang RM, Badano LP, Tsang W, Adams DH, Agricola E, Buck T, et al. EAE/ASE Recommendations for Image Acquisition and Display Using ThreeDimensional Echocardiography. Cardiovasc Imaging. 2012;13:1-46.

14. Rentrop KP, Cohen M, Blanke H, Phillips RA. Changes in Collateral Channel Filling Immediately After Controlled Coronary Artery Occlusion by an Angioplasty Balloon in Human Subjects. J Am Coll Cardiol. 1985;5(3):587-92.

15. Choe JC, Cha KS, Yun EY, Ahn J, Park JS, Lee HW, et al. Reverse Left Ventricular Remodelling in ST-Elevation Myocardial Infarction Patients Undergoing Primary Percutaneous Coronary Intervention: Incidence, Predictors, and Impact on Outcome. Heart, Lung and Circulation 2017, doi:10.1016/j.hlc.2017.02.020.

16. Neumann FJ, Sousa-Uva M, Ahlsson A, Alfonso F, Banning A, Benedetto U, et al. 2018 ESC / EACTS Guidelines on myocardial revascularization. Eur Heart J. 2019;40:87-165.

17. Koitabashi N, Kass DA. Reverse Remodeling in Heart Failure-Mechanism and Therapetic Opportunities. Nat Rev Cardiol. 2012;9:147-57.

18. Mudd JO, Kass DA. Reversing chronic remodeling in heart failure. Expert Rev Cardiovasc Ther. 2007;5(3):585-98.

19. Schwartz H, Leiboff RL, Katz RJ, Wasserman AG, Bren GB, Varghese PJ, et al. Arteriographic predictors of spontaneous improvement in left ventricular function after myocardial infarction. Circulation. 1985;71(3):466-72.

20. Seiler C, Pohl T, Lipp E, Hutter D, Meier B. Regional left ventricular function during transient coronary occlusion: relation with coronary collateral flow. Heart. 2002;88:35-42.

21. Sutton Martin G, Sharpe N. Left Ventricular Remodeling After Myocardial Infarction Pathophysiology and Therapy. Circulation. 2000;101:2981-8.

22. Cohn JN, Ferrari R, Sharpe N. Cardiac Remodeling - Concepts and Clinical Implications : A Consensus Paper From an International Forum on Cardiac Remodeling. J Am Coll Cardiol. 2000;35:569-82.

23. Rahimtoola SH, Canna G La, Ferrari R. Hibernating Myocardium Another Piece of the Puzzle Falls into Place. J Am Coll Cardiol. 2006;47(5):978-80.

24. Bonnow R. The Hibernating Myocardium: Implications for Management of Congestive Heart Failure. Am J Cardiol. 1995;75:17A-25A. 